\title{
Paediatric and neonatal intensive care
}

The major objective of intensive care for infants and children is to provide maximum surveillance and support of organ systems during acute, but reversible, life-threatening illness.' In contrast to adult patients, there are fewer children admitted to intensive care units (ICU's) who suffer from either chronic or degenerative organ systern disorders. Although infants and children with chronic and severe debilitating neurologic and respiratory problems are increasing in prevalence in paediatric intensive care setings, still the majority of children admitted to these units have suffered from or are at high risk for developing a potentially reversible life-threatening illness or injury, which, if successfully treated, will restore the child to a normal, productive life. Recognizing the potential for productivity over a child's life expectancy of 50 to 70 years, the rationale for and the cost of paediatric intensive care is probably justifiable, at least in Western societies.

Although the principles of intensive care for infants and children are similar to those for adult intensive care, the age spectrum from infancy through adolescence requires that the intensive care staff have special expertise in developmental physiology, pharmacology, and psychology. The paediatric intensive care team must be familiar with fetal and neonatal development of children to adulthood. In addition, an understanding of family dynamics and the responses of families to acute or chronic illness in children is essential in managing the complex parental behaviours that often arise during stressful times.

The paediatric ICU is gencrally considered a hospital unit that provides treatment to infants and children having or being at risk for a wide variety of illnesses of a lifethreatening nature. All critically ill children, regardless of diagnosis or subspecialty category, should be cohorted in units dedicated exclusively to children whenever possible. The precise age distribution and spectrum of illnesses will vary considerably from one paediatric ICU to another, on the basis of size, referral pattern, and the surgical activity of their respective hospitals at large

\section{Transporting the critically ill child}

Hospitals with insufficient numbers of paediatric patients to provide specialized facilities for paediatric intensive care should consider transferring critically ill children to a regional paediatric ICU. It is the obligation of regional paediatric ICU's to develop transport systems that will facilitate safe and timely transport of such children to the referral center. In addition, the regional

\author{
Robert K. Crone MD
}

centre should provide medical education in emergency stabilization and critical care paediatrics to primary care and referring physicians and nurses.

The philosophy of transport systems is not only to provide a means of transferring a sick child to a more appropriate facility, but also to institute appropriate intensive care monitoring and treatment to the patient before leaving the referring hospital. More recently, in utero transfer of identifiable high-risk pregnancies to regional obstetric-perinatal centres have been instituted to provide maximal surveillance and support at the time of delivery and have reduced the need for transfer of highrisk neonates after delivery.

The composition of the transport team will vary among institutions but will often be comprised of an $1 \mathrm{CU}$-trained paediatric nurse and paediatric intensivist who, ideally, is trained as a paediatric anaesthetist, since many patients require special expertise in airway management. Transport can be carried out by ambulance, helicopter, or fixed-wing aircraft, depending on local circumstances and distances to be covered. In general, the environment provided by helicopter transport is the most difficult one in which to provide surveillance and treatment due to poor temperature and noise control as well as limited operating space. ${ }^{2,3}$ Communication with the transport team and regional centre is essential in order to facilitate consultation with senior staff and to help the accepting intensive care facility anticipate the nature and degree of illness.

The most serious flaws in the transport system are usually the response time of the transport team once a referral call is made and the availability of on-call transport team members. An institutional commitment of funds, personnel, and equipment along with exceltent organization can ensure that neonatal and paediatric transport systems have a significant impact on patient care, community physician education, and regional hospital referrals.

\section{Recent advances in intensive care management of respiratory failure in infants and children}

\section{Arrificiai surfaciant}

There have been several recent reports of improved outcomes of premature infants with hyaline membrane

Department of Anesthesia, The Children's Hospital, 300 Longwood Avenuc, Boston, Massachusetts, 02115 U.S.A. 
disease (HMD) who were treated with "artificial" surfactant. ${ }^{4.5}$ In one study from the Children's Hospital, Boston, a prospective, randomized controlled trial of exogenous bovine surfactant was conducted in premature infants requiring ventilatory support for the treatment of HMD. ${ }^{6}$ One half of the patients were randomly selected to receive aerosolized bovine surfactant within eight hours of birth, and were shown to have significant improvement in gas exchange and required less ventilatory support within four hours of treatment when compared to saline-treated control patients. It appears from these initial reports of success that the natural history and incidence of HMD in the premature neonatal population may be drastically changed as the clinical use of this agent becomes more widespread.

\section{Negative pressure ventilation}

Body type negative pressure ventilators were popularized by Drinker and associates in 1929 and were used extensively during the polio epidemics of the 1950's. 7,8 These devices have achieved renewed popularity more recently in the management of some forms of respiratory failure in infants and children. Individuals with severe forms of neuromuscular disability, such as Duchenne's muscular dystrophy, and those with chronic obstructive lung diseases, such as cystic fibrosis, have been reported to have sustained improvement in their gas exchange and their general clinical condition when subjected to chronic or night-time home ventilation. ${ }^{9}$ Measurements of vital capacity, inspiratory force, and force of diaphragmatic muscle contraction suggest that this therapy will improve gas exchange, reduce the complications of chronic hypoxaemia and hypercarbia, and prolong life. In addition, there has been a fundamental change in physicians' attitudes regarding the life expectancy of patients with these sorts of "fatal" respiratory diseases. This change has been gencrated in part from the demands of patients and their families as well as the expectation that new forms of therapy, such as lung transplantation, may provide new alternatives for diseases previously considered incurable. In addition, negative pressure ventilation along with other supports at home can provide a tolerable existence for children who previously nceded chronic hospitalization.

Negative pressure ventilation is also useful in weaning some patients from positive pressure ventilation in the ICU under certain circumstances: children requiring prolonged postoperative ventilation due to underlying neuromuscular and pulmonary disease such as those who have undergone surgical correction of scoliosis or infants with congenital diaphragmatic hemia and severe lung dysplasia often can be weaned to the negative pressure ventilator and then extubated. Children will nearly always prefer "tank" ventilation to intubation or tracheostomy, and weaning can be done at a more leisurely pace.
Unfortunately, there are a number of serious conditions which limit the efficacy of negative pressure ventilation. For example, patient size and patient deformities can make the patient-machine interface both difficult and uncomfortable, and the ability to provide basic and specialized patient care can be compromised in these devices. Any degree of upper airway obstruction, be it anatomical or due to tracheal secretions, decreases the effectiveness of air flow. Finally, negative pressure ventilation is not effective in patients with very poor lung compliance: maximal respiratory pressures are $-30 \mathrm{~cm}$ $\mathrm{H}_{2} \mathrm{O}$, and it is not possible to sustain a reliably constant distending airway pressure. The ideal candidate for negative pressure ventilation is one who is cocperative and has only moderate lung dysfunction, a nomal upper airway, and whose support is needed principally for neuromuscular disability.

\section{High-frequency ventilation}

High-frequency ventilation (HFV) describes a pattern of ventilation that can be generated by a number of different types of ventilators: the high-frequency positive pressure ventilator (HFPPV), the high-frequency jet ventilator (HFJV), and the high-frequency oscillator (HFO). Each of these devices differs in technical design and in clinical application and, most likely, differs in the mechanics of gas exchange. ${ }^{10}$ Presently, the HFJV is used most frequently in the operating room for diagnostic and therapeutic airway procedures of a relatively short duration. In the past, concern about inadequate humidification and tracheal damage from entrained gas jets had limited the use of these devices to brief periods of time. Recently, however, these problems have have been addressed satisfactorily such that HFJV may achieve much greater popularity in the intensive care setting. At the present time most HFV in ICU's is being accomplished with HFO devices. These have been used for extended periods of time and have been thought to have the least problems associaled with humidification and tracheal injury.

The rationale for using HFV in infants and children is that normal blood gases can be sustained while exposing the patients' lungs to less barotrauma and less toxic levels of oxygen. Clinical studies are underway to determine whether HFO is less toxic than conventional mechanical ventilation (CMV) when ventilating premature infants with HMD. Preliminary data have been disappointing, however, in that there does not seem to be a difference in survival or in the incidence of bronchopulmonary dysplasia between the HFV and CMV treated groups. ${ }^{11}$

On the other hand, several recent reports suggest that HFO may be a more efficient means of producing hyperventilation in infants with various forms of persistent pulmonary hypertension of the newborn (PPHN) than is CMV. ${ }^{12}$ Infants with both meconium aspiration syn- 
drome as well as congenital diaphragmatic hernia have been reported to have an improved outcome when supported with HFV. ${ }^{13}$ Unfortunately, these studies have relied upon historical control data for comparison and thus are not conclusive. The clearest indication for the use of HFV in infants and children is pulmonary air leak, such as pulmonary interstital emphysema in the newborn and bronchopleural listula in the older child. It is safe to say that the place of $\mathrm{HFV}$ in paediatric respiratory therapy is still emerging and remains unclear at the present time.

\section{Extracorporeal membrane oxygenation}

Despite previous disappointing reports of supporting gas exchange with extracorporeal membrane oxygenation (ECMO) in adults with adult respiratory distress syndrome (ARDS), this relatively invasive form of respiratory support is reemerging as an important modality in treating infants and children with severe lung diseases. ${ }^{14}$ Technical improvements in membrane oxygenators, cannulation techniques as well as a better understanding and monitoring of controlled anti-coagulation have made this technique safer than in the past. Full-term infants with PPHN in association with meconium aspiration syndrome, sepsis, birth asphyxia, as well as congenital diaphragmatic hernia have been successfully supporter with ECMO with a dramatically increased frequency. Although to a lesser degree, children with ARDS have also been supported with ECMO. Recent reports of clinical trials of ECMO in these conditions suggest an improved survival in a selected, albeit uncontrolled, patient population. ${ }^{15,16}$ Again, for the most part, these studies have depended upon historical controls for comparison, thus rendering them inconclusive. At the present time, a prospective, randomized, controlled study is near completion at the Children's Hospital, Boston. Despite the lack of published evidence of efficacy, over 50 centres are presently engaged in ECMO in North America and over 1,000 patients have been supported in this manner. ${ }^{17}$

In addition, despite the previous $\mathrm{NIH}$ experience in adult patients with ARDS, Gattinoni and others from Italy have reported a more favourable experience using less stringent patient selection criteria in ARDS patients while using veno-venous ECMO for $\mathrm{CO}_{2}$ remoyal and lowfrequency positive pressure ventilation for oxygenation. ${ }^{18}$ Unfortunately, these studies are also uncontrolled and thus inconclusive. As is the case with $\mathrm{HFV}$, the place of ECMO in paediatric respiratory therapy remains to be determined.

\section{Allocation of limited intensive care resources}

As medical technology has advanced in paediatric intensive care, so has the cost of medical care escalated dramatically. It appears that although Western societies encourage medical technological advancement we are becoming less enthusiastic about financing it. This fundamental conflict between expectations regarding doing everything possible to treat an individual child and the limitation of available resources has put practitioners of intensive care in the difficult position of rationing care.

Additionally, improper application of intensive care technology to children who are hopelessly ill can often postpone death without necessarily prolonging meaningful life. These financial, legal, and ethical dilemmas are occupying a greater proportion of the intensivist's time. It is clear that these issues need greater emphasis in the education of physicians at large and intensivists in particular. ${ }^{19-21}$

\section{References}

1 Downs JJ, Fulgencio T, Raphaelly RC. Acute respiratory failure in infants and children. Pediatr Clin North Am 1972: $19: 423-40$.

2 Biack RE, Mayer T, Walker ML, et al. Air transport of pediatric emergency cases. N Engl J Med 1982; 307: $1465-7$.

3 Simon JE, Smookler $S, G u y B$. A regionalized approach to peciatric emergency care. Pediatr Clin North Am 1981; 28: 677-88.

4 Raju In, Vidyasagar D, Bhat $R$. et al. Double-blind controlled trial of single-dose treatment with bovine surfactant in severe hyaline membrane disease. Lancet 1987 ; 1(8534): 651-6.

5 Kwong MS, Egan EA, Notter $R H$, Shapiro $D L$. Doubleblind clinical trial of calf lung surfactant extract for the prevention of hyaline membrane disease in extremely premature infants. Pediatrics 1985; 76: 585-92.

6 Gitlin JD, Soll RF, Parad RB et al. Randomized controlled trial of exogenous surfactant for the treatment of hyaline membrane disease. Pediatrics 1987; 79: 31-7.

7 Drinker $P$, Shaw $L A$. An apparatus for the prolonged administration of artificial respiration. $J$ Clin Invest 1929; 7: 229-37.

8 Plum $F$, Lukas DS. An evaluation of the cuirass respirator in acute poliomyelitis respiratory insufficiency. Am J Med 1951; 221; 417-32.

9 Rochester DF, Braun NM. The diaphragm and dyspnea. Am Rev Respir Dis 1979; 77: 119-22.

$10 O^{\prime}$ Rourke PP, Crone RK. High frequency ventilation. JAMA 1983; 250: 2845-7.

11 Lucey J. Proceedings of Controversial Topics in Neonacology; Washington D.C. Dec. 7, 1987. (unpublished)

12 Boynton BR, Manmino FL, Davis RF, Kopotic RJ, Friederichsen $G$. Combined high frequency ventilation and intermittent mandatory ventilation in critically ill neonates. J Pediatr 1984; 105: 297-302. 
13 Bohn D, Tamura M, Perrin D, Barker G, Rabinovitch $M$. Ventilatory predictors of pulmonary hypoplasia in congenital diaphragmatic hernia, confirmed by morphologic assessnent. J Pediatr 1987; 111: 423-31.

14 Short BL, Pearson GD. Neonatal Extracorporeal Membrane Oxygenation: a review. J Int Care Med 1986; 1: $47-53$.

15 Splaingard ML, Frazier H, Jefferson LS, Stein F, Harrison GM. Extracorporeal membrane oxygenation: Its role in the survival of a child with adenoviral pneumonia and myocarditis. S Med J 1983; 76: 1171-3.

16 MacDonnell KF, Moon HS, Sekar TS, Ahluwalia MP. Extracorporeal membrane oxygenator support in a case of severe status asthmaticus. Ann Thorac Surg 1981; 31 : $171-5$.

17 ECMO Registry, University of Michigan. (unpublished data)

18 Kolobow $T$, Gartinani $L, T o m l i n s o n ~ T$, Pierce JE. An alternative to breathing. J Thoracic Cardiovase Surg 1978; 75: 261-6.

19 Meisel A, Grenvik A, Pinkus RL, Snyder JV. Hospital guidelines for deciding about life-sustaining treatment: dealing with health limbo. Crit Care Med 1986; 14: 23946.

20 Uhimann $R F$, Cassel $C K, M c D o n a l d W J$. Some treatment withholding implications of no-code orders in an academic hospital. Crit Care Med 1984; 12: 879-80.

21 Coptan J. Wrongful life and wrongful birth: new concepts for the pediatrician. Pediatrics 1985; 75: 65-72. 